\title{
Procurar a identidade através das imagens: I don't live here anymore
}

\author{
Marta Cordeiro \\ Escola Superior de Teatro e Cinema, Instituto Politécnico de Lisboa, Portugal
}

DOI: https://doi.org/10.31492/2184-2043.RILP2020.38/pp.145-156

\begin{abstract}
Resumo
O artigo procura contextualizar o humano enquanto "ser dividido" - entre a totalidade e a falta; entre corpo e mente - e discutir a ideia de identidade contemporânea enquanto projeto. Utiliza a hipótese de Paul Ricoeur relativamente a uma possível "identidade narrativa", feita da mesmeidade e da ipseidade, e associa a construção identitária à construção da aparência/ corpo. Para isso, analisa os percursos de construção dos sujeitos na contemporaneidade. Discute o trabalho do artista plástico Ugo Rondinone, na série I Don't Live Here Anymore (série de fotografias em que o rosto do artista é adicionado a corpos de modelos, retirados das imagens que circulam nos media) enquanto possibilidade de metáfora acerca da procura de construção da identidade e aponta as possibilidades da imagem enquanto motor de busca permanente dessa construção identitária.
\end{abstract}

Palavras-chaves: identidade; corpo; Ugo Rondinone; imagem.

\section{Abstract}

The article seeks to contextualize the human as a" divided being" - between the totality and the lack; between body and mind - and discuss the idea of contemporary identity as a project. It uses Paul Ricoeur's hypothesis regarding a possible "narrative identity", made of sameness and ipseity, and associates the construction of identity with the construction of appearance / body. For this, it analyzes the construction routes of the subjects in the contemporaneity. Discusses the work of the plastic artist Ugo Rondinone in the series I Don't Live Here Anymore (series of photographs in which the face of the artist is added to the bodies of models, taken from the images that circulate in the media) as a possibility of metaphor about the search of identity construction, and points out the possibilities of the image as a permanent search engine of this identity construction.

Keywords: identity; body; Ugo Rondinone; image.

\section{Ser um sendo dividido}

É possível que uma das definições plausíveis de humanidade se encontre com a ideia de busca ou procura permanente. N'O Banquete, Platão coloca no discurso de Aristófanes a explicação do sentimento de incompletude do humano, dizendo ter existido, em tempos, a raça andrógina, composta por masculino e feminino em que,

Cada homem, no seu todo era de forma arredondada, tinha dorso e flancos arredondados, quatro mãos, outras tantas pernas, duas faces exatamente iguais sobre um pescoço redondo e, nestas duas faces opostas, uma só cabeça, quatro orelhas, dois órgãos sexuais, e tudo o resto na mesma proporção. (Platão, 1986, p.59, 190a) 
Estes seres esféricos, vigorosos e corajosos, desafiaram os deuses e, em consequência, Zeus decidiu ferir a força desta raça, separando em dois o que antes era uno: «De cada vez que cortava um, ordenava a Apolo para lhe voltar a face e o pescoço para o lado do golpe, a fim de que, vendo-o, o homem se tornasse mais humilde» (Platão, 1986, p.61, 191a) e curava-lhe a feridas, deixando o umbigo como memória do castigo. Desde essa época, cada metade procura a outra, desejando fundir-se nela e é o Amor o veículo desta tentativa de união, «O amor tende a reencontrar a antiga natureza, esforça-se por se fundir numa só, e por sarar a natureza humana» (Platão, 1986, p.62, 191d).

É possível que qualquer das definições que designam a identidade humana se fundem em mitos ou lendas. Trata-se, muitas das vezes, de explicar o sentimento que se encontra por debaixo da ideia de identidade, frequentemente relacionado com o pressentimento de uma "falha", uma "fenda" que não se pode remediar. O sentimento de ser humano está saturado da intuição de uma dilaceração primordial, a que muitas narrativas vão respondendo ou encontrando justificação (não sendo de excluir a possibilidade inversa, a de a cultura criar ou alimentar a ideia de uma angústia primordial). George Steiner (2015) utiliza a metáfora da «nostalgia do absoluto» ou da «tristeza do pensamento» para designar a necessidade de encontro com o metafísico, ou para justificar a impossibilidade de deixar o trabalho do pensamento e apaziguar a procura infinita - sendo o infinito a tarefa eminentemente humana, a «tarefa infinita» como motivo da filosofia ocidental ${ }^{1}$.

As cisões que formam o humano serão várias (desde a narrativa que apresenta o homem cortado em dois e justifica a busca pela metade amada - justifica o amor dos amantes) mas, pelo menos duas delas, podem ser tidas como universais: aquela que implica a separação do humano de uma totalidade mítica e uma outra, em que duas substâncias que são o sujeito se encontram como estranhas, o corpo e a mente.

A arte - ou a identificação do sujeito com a imagem - é o meio e o momento em que o indivíduo se separa da amálgama da Natureza, colocando-se na posição de artista e de espectador. A propósito do mito de Narciso, Rosalind Krauss (1999, p.90) reconhece na verticalidade do corpo humano a possibilidade do indivíduo ser «sujeito da contemplação», conquistando a distância necessária ao domínio (através do olhar) e à reflexão crítica, por oposição aos animais, obrigados a tocar o que veem.

De forma ainda mais evidente, a mão negativa impressa na Gruta de Chauvet ${ }^{2}$ implica um processo de distanciamento em relação ao todo, um recuo e um impulso

1. Referência ao conceito de Edmund Husserl. (Husserl, 1935).

2. Pinturas rupestres das paredes de uma gruta francesa; encontram-se representações de mãos em negativo e positivo. 
que impele o Homem no sentido da construção icónica de si. Marie-Jose Mondzain descreve o processo isolando três momentos: a mão que se posiciona; o sopro; o retrato. Desta triologia resulta a produção da sua imagem, a possibilidade de se dar a ver «como um traço vivo separado de si» (Mondzain, 2010, p.53) . $^{3}$ Neste sentido, e segundo a autora, o importante é o gesto inaugural e a imagem como gesto constitutivo que isola o sujeito falante e desejante, permitindo-lhe o reconhecimento de si e do outro.

Este sujeito separado do todo convive, dentro das suas fronteiras, com a dissidência das matérias que o compõem, cisão histórica e culturalmente realizada mas que acompanha o sentimento de ser humano.

Na moral socrático-platónica a inevitabilidade da procura é constante: a procura do amado, a procura de união ao Universal, sendo a alma conduzida pelo desejo de Verdade até ao encontro com o que lhe é semelhante. No Fédon, a pretexto de narrar o episódio da morte de Sócrates, Platão apresenta, pela primeira vez e de forma sistemática, as razões que justificam a imortalidade da alma. Ao longo do último diálogo que mantém com os discípulos, Sócrates avança quatro argumentos que justificam a teoria e separam a natureza imortal da alma da condição perecível do corpo. Através da alma, seria possível encontrar a verdade; o corpo, visto como o polo negativo, não seria mais que uma prisão da alma:

\footnotetext{
Inúmeros são, de facto, os entraves que o corpo nos põe, e não apenas pela natural necessidade de subsistência, pois, também doenças que sobrevenham podem ser outros tantos impeditivos da nossa caça ao real. Paixões, desejos, temores, futilidades e fantasias de toda a ordem - com tudo isso ele nos açambarca, de tal sorte que não será exagero dizer-se, como se diz, que, sujeitos a ele, jamais teremos disponibilidades para pensar. (Platão, 2001, p.52)
}

Caberia ao filósofo um esforço no sentido de, ao longo da vida, permitir o mínimo contacto entre alma e corpo, não deixando que as necessidades do segundo corrompessem a primeira e, deste modo, preparar-se para a recompensa da vida ao lado dos deuses e demais homens sábios. Aquele que, na terra, se deixasse corromper pelos desejos do corpo, sofreria o castigo despenhando-se no abismo do Tártaro, donde não mais regressaria ${ }^{4}$.

Relativamente à justificação da imortalidade da alma, a primeira ideia é a de que todas as realidades nascem do seu contrário e, tal como o justo nasce do

3. «Se retirer pour produire son image et la donner à voir aux yeux comme une trace vivante séparée de soi».

4. Os que, em terra, haviam cometido grandes crimes (homicídios, roubos), despenhar-se-iam no Tártaro; os que, não vivendo de forma exemplar também não tivessem cometido faltas (tão) graves, permaneceriam em Aqueronte, um lago à beira do qual aguardariam até se purificarem. Mas, para os que houvessem cometido um grande crime num momento de cólera e dele se houvessem arrependido durante a vida, existiria uma segunda oportunidade: depois de, por um ano, permanecerem no Tártaro, regressariam a Aqueronte até se purificarem (Platão, 2001, pp.117-118). 
que era injusto, ou o maior do menor, também o "estar morto" decorre do "estar vivo". Assim, e de forma recíproca, também o vivo nasce do morto, donde, seríamos levados a considerar o facto da alma sobreviver à morte do corpo e vir a animar a geração dos vivos. Este primeiro argumento encontra seguimento no segundo; nesta fase do diálogo, Sócrates isola determinados conceitos - a Igualdade, o Bem, o Belo -, impossíveis de serem apreendidos pelos sentidos e, observando que os indivíduos se encontram na posse destes conceitos apesar de não terem possibilidade de os conhecer por intermédio da experiência conclui que, durante a vida terrena, o ser humano recorda conhecimentos que estavam na posse da alma, antes de esta incarnar no corpo. Assim, a alma existiria antes do corpo e conhecer seria recordar. Seguidamente, Sócrates distingue a natureza do corpo e da alma: o corpo é material, visível e a alma invisível e não material. Aquando da morte, o corpo segue o caminho do que lhe é semelhante, corrompendo-se e decompondo-se; a alma, que se assemelha ao divino, por não ser uma substância composta, manteria a sua identidade e não encontraria um processo de decomposição, ou seja, não morreria. O último argumento, que retoma a ideia do anterior, defende que a natureza da alma é idêntica à das ideias puras. Aceitando que é a alma que, ao manifestar-se no corpo, lhe confere vida, jamais aceitaria algo de natureza oposta à sua, ou seja, a alma que é vida excluiria a morte.

Por ter a certeza da imortalidade da alma, Sócrates mantém-se sereno e aceita com confiança beber o veneno que lhe destinaram e diz aos discípulos: «Por mim, eis já chegada a minha hora, como diria um herói trágico, e pouco mais me resta do que ir para o banho: julgo, com efeito, preferível fazê-lo antes de beber o veneno e poupar assim as mulheres ao incómodo de lavarem um cadáver» (Platão, 2001, p.119).

Esta estrutura, que separa corpo e alma e atribui à alma a conotação com o Bem, o Belo e a Verdade perpetuou-se na cultura ocidental, nomeadamente através da sua apropriação pelo Cristianismo e veio a ser fortemente criticada por Nietzsche que exigiu a valorização do corpo e da vida na Terra: «Eu sou corpo e alma. (...) a alma é uma palavra que designa uma parte do corpo. (...) Habita o teu corpo, é o teu corpo. Há mais razão no teu corpo do que na própria essência da tua sabedoria» (Nietzsche, 2005, p.26).

O corpo sempre foi importante e sempre foi utilizado politicamente, pois foi sempre o meio de dar a ver a consonância ou discordância relativamente aos modelos sociais vigentes. Considerar o corpo enquanto polo negativo, "desprezar o corpo" 5 é reconhecer a importância do corpo, devendo a aparência dos indivíduos ajustar-se ao que se considerava ser a virtude - castrar, oprimir, regular o corpo 
como forma de controlar a moral e o papel social dos indivíduos. Mas o eco das palavras de Nietzsche na contemporaneidade colocou o corpo como matéria da responsabilidade de cada sujeito, o corpo enquanto matéria que espelha as escolhas de cada um, que se apresenta enquanto mostruário de opções, que constrói verdadeiramente a identidade dos indivíduos.

\section{Identidade e aparência}

A contemporaneidade trouxe a novidade da escolha. Escolher para lá dos papéis destinados aos indivíduos nas comunidades pré-modernas, dependentes de rituais e projetos fixos e cíclicos; escolher para lá dos papéis determinados pelo nascimento. Nas sociedades ancestrais, ao nascer, o sujeito conhece as linhas gerais que devem reger a sua existência, marcada pelos ritos de passagem; a modernidade altera profundamente este entendimento quando assume uma identidade processual e projetual, numa primeira instância limitada pela regulação das instituições (a religião, o Estado e a família) e pelas grandes categorias modernas de raça, género e classe e, na atualidade, plenamente assumida como um projeto da responsabilidade de cada indivíduo que deve, em cada momento, fazer escolhas que definam quem é e, para tanto, ser flexível de forma a adaptar-se aos contextos em que atua e se move.

A contemporaneidade trouxe a novidade da escolha e a possibilidade efetiva de consumar essa escolha, certamente dependente da real implantação do mercado de massas pós revolução industrial, que elegeu o consumo como meio de construção e demonstração da identidade. A outra face da liberdade é a responsabilidade pois, se cada sujeito é obrigado a escolher quem é, é igualmente responsabilizado - com o sucesso ou falta dele - por essas escolhas. Num contexto híper-mediatizado, em que a imagem assume uma importância avassaladora e se diz que o mundo se transformou numa imagem (fórmula redutora mas que assume a imagem enquanto possibilidade de acesso ao real $^{6}$ ), as imagens propostas pelos media assumem o papel de conselheiros dos indivíduos. As personalidades que surgem rotineiramente nos media apresentam-se como possibilidades de modelos a seguir e o sucesso e estatuto social de que dispõem, o seu capital mediático e simbólico (o status e a «estima social» ${ }^{7}$ ) funciona, para os indivíduos, como garantia.

6. W.J.T. Mitchell designa a atual relevância das imagens enquanto modo de pensamento como the pictorial turn. A este propósito, V. Iconology. Image, Text, Ideology, Picture Theory, What do Pictures Want? The lives and Loves of Images.

7. Referência ao conceito de status, de Max Weber e ao de «estima social» de Pierre Bourdieu.

"Status" shall mean an effective claim to social esteem in terms of positive or negative privileges; it is typically founded on a style of life» (Weber, 1978, p.305). V. também (Bourdieu, 1984, p.5). 
Neste contexto, a construção das identidades encontra-se ligada aos modelos difundidos pelos media - que têm como figura de síntese a das designadas "celebridades" - e à capacidade de alterar o corpo e a aparência em função da expressão desse projeto identitário.

A ideia de projeto, até aqui arredada da discussão em torno da identidade e do corpo, passa a designar a necessidade dos indivíduos se reinventarem e adaptarem a situações que mudam de forma rotineira e acelerada. Anthony Giddens relaciona a identidade contemporânea com o conceito de "estilo de vida", um «conjunto mais ou menos integrado de práticas que um indivíduo adota não só porque essas práticas satisfazem necessidades utilitárias, mas porque dão forma material a uma narrativa particular de autoidentidade» (Giddens, 2001, p.75). Esta realidade não se adequa às culturas pré-modernas porque implica diretamente a escolha individual e o risco decorrente, não podendo ser transmitida ou herdada. Neste sentido, escolher, implica estar aberto à pluralidade de opções, questão sintetizada na ideia de Zygmunt Bauman (195, p.88) fala do "corpo fitness", aquele que tem a capacidade de se adaptar e aceitar as experiências que a vida propicia. Em harmonia, este corpo abraça o "eu performativo", especialmente orientado para a autoexpressão e procura do prazer, que Mike Featherstone (1991, p.88) relaciona com o atual culto das celebridades, que minam o imaginário dos indivíduos com imagens de beleza e sofisticação, que passam a figurar como estilos de vida a seguir.

Na obra O Si Mesmo como Outro, Paul Ricoeur (1991) identifica duas modalidades de funcionamento no interior da lógica da construção da identidade: a mesmeidade e a ipseidade. A ideia de identidade encontra-se impregnada da necessidade de mesmeidade, que diz respeito aquilo que é contínuo, organizado e linear; ao carácter imutável do sujeito, capaz de atravessar o tempo e manter a possibilidade de reconhecimento de si. Em simultâneo, a lógica da ipseidade interpela o sujeito enquanto construção, vontade e promessa e aponta para a realização do sujeito no ato do fazer, para a fragmentação e possibilidade de construção da identidade através de um percurso narrativo. Ou seja, num indivíduo, para além do que é constante (o mesmo) existe o descontínuo, o eu que existe como sujeito do fazer e que se realiza no percurso de uma narrativa. Neste sentido, Ricoeur avança a ideia de «identidade narrativa» enquanto capacidade de descrever o percurso contemporâneo: a história de vida em paralelo com a construção da identidade; a função da narrativa como mediação entre o que é instável - a ipseidade - e a coerência da história, durante a qual e apesar das variações no personagem, é possível identificar a existência de um personagem, o mesmo. 
Desta interpelação da ipseidade, da assunção da necessidade de mutação e adaptação do projeto identitário resulta, por um lado, a capacidade de assumir um papel criativo e com um grau de liberdade considerável na gestão do eu mas, igualmente, o sentimento de que esse eu construído escorrega, não se fixa, falha:

\begin{abstract}
It soon transpired that the real problem is not how to build identity, but how to preserve it; whatever you may build in the sand, it is unlikely to be a castle. In a desert-like world it takes no great effort to blaze a trail - the difficulty is how to recognize it is a trail after a while. How to distinguish a forward march from going in circles, from eternal return? It becomes virtually impossible to patch the trodden stretches of sand into an itinerary - let alone into a plan for a life-long journey. (Bauman, 1995, p.88)
\end{abstract}

\title{
3. Estar ali
}

Em 1995 o artista Ugo Rondinone iniciou a série I Don't Live Here Anymore, fotografias de cerca de $150 \times 100 \mathrm{~cm}$, trabalhadas digitalmente. Em cada uma, Rondinone adiciona a sua face à imagem de corpos de modelos, imagens colecionadas em revistas de moda que representam corpos de jovens ou de adolescentes em poses sensuais. $\mathrm{O}$ vínculo que o título e a utilização da sua face estabelece com o "eu" remete para a ligação direta entre "quem eu sou", "qual a minha identidade" e a imagem, como se em cada fotografia se procurasse aceder a uma identidade particular, obtida na experimentação de um corpo.

O corpo assume um carácter determinante na construção efetiva da identidade, que se estabelece nesta deriva pela imagem, dando forma material à metáfora que Bauman utiliza ao identificar a identidade contemporânea com a figura do peregrino. Bauman alerta para a dificuldade na construção de um projeto coerente quando é necessária a adaptação permanente à reflexividade contemporânea. Neste contexto, Giddens (2001, pp.16-17) distingue a monitorização reflexiva da ação, inerente a qualquer atividade humana, da reflexividade moderna que deriva da rapidez e constância do fluxo de informação e que substitui as certezas fundacionais pré-modernas pelo critério da dúvida, obrigando a que os sujeitos adaptem as suas ações constantemente, o que obriga à reformulação periódica da identidade. Neste contexto, a escolha de imagens de corpos adolescentes sublinha o carácter provisório da identidade, assinalando-se a adolescência como época de alterações constantes, decisivas e rápidas.

O trabalho sobre o corpo coincide, aqui, com o trabalho sobre a identidade mas releva-se o facto de os corpos selecionados não serem quaisquer uns, são antes retirados do conjunto das "celebridades" que são assinaladas como caso em que a aparência se separa do "verdadeiro eu", que passa a estar concentrado num comportamento público ou abreviado numa função. A publicidade faz sobressair esta operação de redução quando relaciona o produto, o corpo do modelo que o 
publicita e a qualidade associada a ambos: $x$ utiliza o champô y e é atraente, logo, o champô y torna os utilizadores atraentes, logo, semelhantes a x. Na moda, o processo é semelhante, podendo a coleção do costureiro e a aparência dos modelos que a promovem ser associada a irreverência, glamour, determinação, sucesso, etc. No limite, um objeto e o modelo podem surgir associados a qualquer significado, processo que Baudrillard descreve ao analisar a complexificação da estrutura do signo, tornando polivalente a relação entre significante (Ste) e significado (Sdo) - a estrutura do signo é arbitrária pois a relação entre significante e significado é uma convenção que, em princípio, é de tipo exclusivo; é a substituição da univocidade pela multiplicidade que caracteriza a transformação da arbitrariedade do signo:

A racionalidade do signo funda-se na exclusão, na aniquilação de toda a ambivalência simbólica, em proveito de uma estrutura fixa e equacional. O signo é um discriminante: estrutura-se por exclusão. (...) Esta consignação do Ste e do Sdo termo a termo pode muito bem complexificar-se numa relação equívoca, multívoca, sem infringir a lógica do signo. Um Ste pode remeter para vários Sdo, ou inversamente: o princípio de equivalência, portanto de exclusão e de redução sobre o qual se funda o arbitrário, permanece o mesmo. A equivalência tornou-se simplesmente polivalência. (Baudrillard, 1982, p. 186)

Colocar o "eu", metaforicamente condensado no rosto, no interior de um corpo corresponderia, então, a procurar traduzir o "eu” pelas qualidades apresentadas. A identificação entre o "eu" como interioridade subjetiva e a qualidade publicitada pela imagem mantém a estrutura tradicional que associa o interior ou a alma e o Bem pois, ainda que a atualidade reforce a necessidade de expressar na imagem a personalidade de cada indivíduo, parte do princípio que esta personalidade é "boa", por isso digna de ser mostrada. Nesta equação tradicional falta a beleza como condição de transporte até ao Bem, sendo conhecida a justificação neoplatónica utilizada desde a Renascença para a representação do corpo nu, a de que a beleza divina se expressa na harmonia do corpo e do mundo. Esse meio de transporte continua a ser o do corpo: um indivíduo adquire um produto (o mesmo champô que usa um modelo, por exemplo), para ser atraente, mas ser atraente à semelhança do modelo, ser atraente tal como aquele corpo belo o é. O lugar onde a imagem se abre à projeção por parte do espectador é o do corpo do modelo pois, como é sabido e James Elkins (1996, p.120) reforça, o olho humano está desenhado para ver corpos uma vez que, em cada imagem, se procura o que é semelhante a si próprio, um doppelgänger ou um gémeo.

Em I Don't Live Here Anymore, Rondinone projeta-se e concretiza a projeção, colando o seu rosto ao corpo dos modelos. No entanto, assinala a impossibilidade 
do encontro ao deixar clara a montagem: ao invés de utilizar os softwares de manipulação de imagem para iludir a junção, deixa em todas as imagens da sua face sombras - sombras de fim-de-tarde (Janus, 1998) - que ameaçam a coerência interna da fotografia e denunciam a sua "falsidade". A falha no encontro entre Rondinone e a imagem ideal também existe na própria duração da obra (iniciada em 1995 e com fotografias de 2011), prolongamento que atesta a recorrente insatisfação e o carácter provisório e precário de cada investida. Destes (des)encontros resulta uma dúvida acerca da identificação entre interior e exterior, bem como uma paródia à tradição ocidental segundo a qual a imagem reflete a substância.

Para além das propriedades da imagem, o título argumenta a favor deste questionamento pois, ao contradizer a imagem (onde Rondinone efetivamente está representado), explora a fenda que existe entre imagem e linguagem, num processo de negação (isto não é aquilo) que recorda Ceci n'est pas une Pipe (1928-29) de René Magritte. Aqui - e de acordo com Foucault ${ }^{8}$ - a legenda afirma o óbvio, não é um cachimbo mas a representação de um cachimbo mas, ao fazê-lo, põe em causa uma atitude convencional que tende a tratar a imagem como a coisa em si (Mitchell, 1995, p.66). Também Rondinone afirma, "não vivo aqui”: I (eu) não estou aqui (here) e "aqui" é um advérbio que, juntamente com "eu", situa o indivíduo no "sítio onde está" - a imagem. Pode dizer-se que o I não está ali, no sentido em que "ali" seria apenas uma representação e não o sujeito em si quando, para mais, o "ali" da fotografia não passa de uma montagem e não existe uma relação de veracidade entre referente e fotografia. Nesta hipótese, $I$ seria o indivíduo "de carne e osso", exterior à representação.

H. P. Grice (1941) enumera várias tipologias de frases onde I é utilizado: 1) «I am hearing a noise.»; 2) «I played cricket yesterday.»; 3) «I was hit by a golf-ball.». Nas frases de tipo 3, afirma ser possível substituir I por "my body", obtendo «My body was hit by a golf-ball.» e mantendo o sentido original. Esta substituição parece inviável nos tipos 1 e 2 , sendo que 2 é tido como exemplo de transição, pois é verdade que "o meu corpo joga cricket", mas é igualmente verdade que é algo mais que apenas "o corpo" que joga cricket. Finalmente, no tipo 1), o I não pode ser substituído por "my body" - não é "o meu corpo" que ouve um ruído. As frases de tipo 1 relacionam-se com a interioridade de

8. Em Ceci n'est pas une Pipe, Magritte utiliza "Isto" para apontar a imagem, interpelando o espectador - "Isto" não é “aquilo". Neste caso, «Magritte liga os signos verbais e os elementos plásticos, mas sem se outorgar, previamente, uma isotopia; esquiva o fundo de discurso afirmativo, sobre o qual repousava tranquilamente a semelhança: e coloca em jogo puras similitudes e enunciados verbais não-afirmativos, na instabilidade de um volume sem referência e de um espaço sem plano. Operação da qual Isto não é um cachimbo dá, de certo modo, o formulário.» (Foucault, 2007, p.76) 
que Elizabeth Grosz (1995, pp.33-35) fala quando separa o corpo em exterior e interior e o exemplo apresentado coaduna-se com a afirmação de W.J.T. Mitchell (1995, p.269) que diz que o significado de I depende da sua utilização: pode não se referir nem ao corpo, nem ao "eu" pois o seu lugar é determinado por um discurso específico.

Rondinone condiciona a interpretação da utilização de $I$ ao utilizar live (e não, por exemplo, I am not here anymore) e anymore - live ou viver numa imagem ou num corpo remete para viver num habitáculo, ou habitar alguma coisa, ação que depende da existência de um exterior que contém um interior. Depois, se o I não está ali anymore, supõe-se que em algum momento já esteve e que, por isso, existe um $I$ que habitou um corpo ou uma imagem e o/ a abandonou. Em princípio, então, o $I$ de Rondinone refere-se à sua interioridade ou identidade, que não se consegue concretizar nas imagens modelo difundidas pelos media.

"Eu não vivo aqui": um "aqui” que é simultaneamente referência à materialidade do corpo e à função da imagem. O facto de, ao longo da série, Rondinone percorrer vários corpos aponta para o questionamento de uma identidade fundada sobre o corpo (e é também possível refletir acerca da relação entre género e identidade). Simultaneamente, utiliza a aceção tradicional que conota a profundidade da imagem com o lugar da Verdade que, no corpo, se traduz na existência de uma alma (o Bem) para lá do corpo. Neste caso, o artista esvazia a imagem da sua função de contentor, distanciando-se da esperança da filha de Butades (que quis guardar a alma do amado numa imagem ${ }^{10}$ mas, também, da aceção platónica que conota as imagens com a apresentação de sucedâneos (eidola ou phantasmata) das ideias puras. Finalmente - e tratando-se da face de Rondinone - desvia-se da função tradicional do autorretrato que coloca o artista em posição frontal, a olhar o espectador e a deixar que, através dos olhos, seja espelhada a alma.

As imagens de Rondinone estão libertas do peso de serem contentores porque são apenas superfície e assumem plenamente a falha no encontro entre a interioridade e uma aparência modelo. É esta falha que Roland Barthes identifica quando diz, a propósito da fotografia, que "eu" nunca coincido com a minha imagem, « porque é a imagem que é pesada, imóvel, obstinada (aquilo em que a sociedade se apoia), e "eu” que sou leve, dividido, disperso» (Barthes, 2006, p.20).

9. Na obra Space, Time and Perversion, Elizabeth Grosz isola duas perspetivas de análise do corpo: a que denomina de «inscrição» (inscription) - e que relaciona com um corpo público, social, que funciona como superfície de inscrição da moralidade e da lei social - e a perspetiva do «corpo vivo» (lived body), adida da fenomenologia e psicanálise e que se debruça sobre a esquematização de uma anatomia imaginária.

10. Lenda narrada por Plínio, que conta a história da filha do ceramista Butades que, antes de o amado partir para a guerra, desenhou a sua silhueta contra uma parede procurando, através da imagem, guardar a alma do amado.(Pline L'Ancien, 1985, p.63). 
Paradoxalmente, enquanto Rondinone denuncia a reciprocidade interior/ exterior, mantém a estratégia da busca e da construção da identidade através da imagem, continuando a produzir fotografias onde a sua face se acomoda aos corpos dos media. Nesta demanda, torna visível a capacidade de a imagem seduzir o espectador e se constituir como local de projeção e de não existir alternativa ao corpo e à imagem como local de construção da identidade, não existindo alternativa, ainda, ao modo peregrino da identidade.

\section{Considerações finais}

A aceitação da identidade enquanto projeto e processo, abrindo mão de uma suposta coerência decorrente da lógica da mesmeidade enquanto lógica única, coaduna-se e reforça o sentimento de ser humano enquanto sentimento de se ser contruído sobre uma "falha" ou "fenda", que permanece como substrato. A identidade - quem eu sou -, para além de manter a instabilidade e impossibilidade de ser circunscrita (como solicitação do contexto contemporâneo), mantém-se como narrativa impossível de relatar fiel e decididamente, pois as palavras são escassas e avessas à descrição de coisas móveis, que se metamorfoseiam, que escapam e escorregam. Henri Bergson (2001, p.148) distingue o que é estável e pretende cristalizar - a palavra - e o que é móvel e não aprisionável, como a experiência; a palavra dificilmente torna claro o sentimento de ser humano ou, mesmo, o que eu sou, qual a minha identidade.

Neste contexto, a imagem, que funciona como modo alternativo de dizer sem pretender cristalizar, a imagem que funciona através da composição e da criação de «blocos de sensações» ${ }^{11}$, pode transmitir, através da lógica da intuição, estes sentimentos não dizíveis. $\mathrm{O}$ trabalho de Rondinone tem a capacidade de ser um documento, um texto, capaz de interpretações e análises várias. Mas, como imagem - como polissemia [no sentido em que Roland Barthes (1988, p.27) identifica a capacidade que a imagem tem de exceder a palavra, juntando mensagem e significados potenciais] - mantém a capacidade de ser interpretada potencialmente, deixando o espectador com a sua interpretação e, por debaixo dela, a intuição de aceder, mesmo que momentaneamente, ao estar - ser o modo peregrino de ser humano.

11. Referência a Gilles Deleuze quando aponta a especificidade da arte através da produção de "blocos de sensações", relevando a ideia de composição enquanto modus operandi da produção artística (Deleuze e Guattari, 1992). 


\section{Referências}

Barthes, R. (1988). Retórica da Imagem. In Mitologias. Lisboa: Edições 70.

Barthes, R. (2006). A Câmara Clara. Lisboa: Edições 70.

Baudrillard, J. (1982). Para uma Crítica da Economia Política do Signo. Lisboa: Edições 70.

Bauman, Z. (1995). Life in Fragments - Essays in Postmodern Morality. Cambridge: Blackwell.

Bergson, H. (2001). A Evolução Criadora. Lisboa: Edições 70.

Bourdieu, P. (1984). Distiction: A Social Critique of the Judgement of Taste. USA: Routledge $\&$ Kegan Paul Ltd.

Deleuze, G., Guattari, F. (1992). Percepto, Afecto e Conceito. In O que é a Filosofia? Lisboa: Editorial Presença.

Elkins, J. (1996). The Object Stares Back. On the Nature of Seeing. New York: Simon \& Schuster.

Featherstone, M. (1991). The Body in Consumer Culture. In M. Featherstone, M. Hepworth $\&$ B. Turner (Eds.), The Body: Social Process and Cultural Theory. London: Sage Publications.

Foucault, M. (2007). Isto Não é um Cachimbo. São Paulo: Paz e Terra.

Giddens, A. (2001). Modernidade e a Identidade Pessoal. Oeiras: Celta.

Grice, H.P. (1941). Personal Identity. In G. Moore (Ed.), Mind. London: Macmillan\&Co.

Groz, E. (1995). Space Time and Perversion. Essays on the Politics of Bodies. New York \& London: Routledge.

Husserl, E. (1935). A Crise da Humanidade Europeia e a Filosofia. LusoSofia. Disponível em http://www.lusosofia.net/textos/husserl_edmund_crise_da_humanidade_europeia_filosofia.pdf.

Janus, E. (1998). Ugo Rondinone. Artforum. Disponível em http://findarticles.com/p/articles/ mi_m0268/is_3_37/ai_53286434/.

Krauss, R. (1999). Gestalt. In Y-A. Bois, R. Krauss, Formless. A User's Guide. New York: Zone Books.

Mitchell, W. J. T. (1995). Picture Theory. Chicago: The University of Chicago Press.

Mondzain, M-J. (2010). Le Lieu des Images. In E. Alloa (Ed.), Penser L'Image. France: Les Presses du Réel.

Nietzsche, F. (2005). Dos que Desprezam o Corpo. In Assim falava Zaratrustra. São Paulo: Martin Claret.

Platão (1986). O Banquete. Lisboa: Guimarães Editores.

Platão (2001). Fédon. Lisboa: Lisboa Editora.

Pline L'Ancient (1985). Histoire Naturelle. XXXV. Paris : Les Belles Lettres.

Ricoeur, P. (1991). O Si Mesmo como Outro. São Paulo, Papirus.

Steiner, G. (2015). Dez Razões (Possiveis) para a Tristeza do Pensamento. Lisboa: Relógio d’Àgua.

Weber, M. (1978). Economy and Society. California: University of California Press. 